\title{
New PR strategy under the new media era
}

\author{
Mao Jiaqi ${ }^{*}, 1, \mathrm{a}$, ,Zhao Xuan ${ }^{*}, 2, \mathrm{~b}$ \\ *These two authors contributed equally to this work \\ 1.48 Huzhou street Gongshu area Hangzhou Zhejiang China \\ 2.48 Huzhou street Gongshu area Hangzhou Zhejiang China \\ a. Email: 825379816@qq.com \\ B. Email:373908464@qq.com
}

Keywords: New media; PR strategy;

\begin{abstract}
Network and digital field have made new breakthroughs under the new information circumstances, resulting the presence of numerous new forms of media. This article attempts to take the public dissemination of new media form as the research object, analyze the main characteristics and development of the new media in the new media era, and aims to provide new PR strategies according to challenges and opportunities resulting from the new media.
\end{abstract}

\section{Introduction}

First of all, we should have a general understanding of the new media. "There are diverse forms of new media, network technology and digital technology are fundamental cornerstones of the new media.The traditional media such as radio and television, newspapers, periodicals etc, are too changeless relative to the new media. Their form will limit their Communication area. The "new" of the new media is more reflected in the form of technology level. Internet is an admirable modality of the new media, and both the network television and electronic newspapers take the traditional media as foundation and reflect the combination of old and new way.

In recent years, the drastic development of the new media technology has showed numerous characteristics that are difference from traditional forms of the media.The rapid progress of the new media technology makes the public relation face more corresponding changes. Currently, the PR dissemination in the new media ear has became a hot topic and more and more people begin to pay attention to new changes in this field.

\section{The transformation and development of PR}

In past public relations dissemination process, propagator should share information with the public and influence public attitudes to make the public get interest in understanding the organizations. But in the public relations dissemination process which is under the new media environment, individuals can become the center of the communion, which makes objects of current PR dissemination relationship become fuzzy. Accordingly, public relations forms which rely on the traditional media have got more space for development.

\section{The subjectivity of PR and the influence of propagator are strengthened.}

Different from the traditional dissemination conducted by formal and legal organization, the subject of public relations has been expanded, not only units and organizations, but the individuals can have a chance to become the main object in communication process, which increases dramatically the number of propagators under the new media environment. Such condition adds the frequency and scope of the existing PR dissemination. With the attraction of profits and development, the existence of numerous new public organizations has enriched the form of mass communication, and makes subjects win a landmark expansion.

Because the PR used to rely on the traditional public media, the development of propagator lacks initiative and independence. With the development of modern science and technology, the 
new media has been used widely, and the propagator of PR has new weapons to spread useful information. Such as the most direct and rapid media with sharp growth: Facebook, Weibo, Wechat, blogs and other forms of communication can give the public a chance to get rapid communication and feedback and ensure autonomy , timeliness and controllability of the propagator.

\section{The explosion of dissemination.}

With the development of satellite TV and digital TV, the traditional media win a wider range of audiences; rich contents of dissemination have given the public more choices for programs. But in terms of network TV, viewers can download and store any videos according to their own preferences. This feature caused explosive growth of audiences and high-speed expansion the of new media, which makes network become a communication platform that is without any limitation to boundaries and time. Additionally, the contents can better meet the demand of public's taste , and win objective and extensive audience market.

New objects give a chance to produce new channels.

A notable reason why the new media can become the new communication channels is that it can find the spread blind spot and audience's contact point which traditional media cannot fails to achieve, and thus fully occupies the market and objects. Through the network, objects can get the information of emergent incidences at first time, which causes great changes of technology and processing methods in journalism and public sector. From quick releasing and clicking the simple graphics and fast texts even short videos, useful social news are pushed to the public at the moment of information explosion.Meanwhile, it can stimulate audience contact points of all aspects in the society. There are various advanced media forms such as LED touch screen, outdoor LED and new mobile multimedia etc.

\section{Transform and development between subjects and objects.}

Special characteristics of the new media eliminates the one-way communication mode of PR communication.Continuously improved the power of public opinion and influence makes objects become more active in public relations. That means that the subject of PR has lost the power called "mandatory" in traditional media era. The relationship between the subject and the object turns into controller and anti controller.Accordingly, under the new media era, the status of the subject and object becomes more equal. The mode of Two-sided communication of public relations has become more important.

\section{The strengthening of public influence and status.}

In the new media environment, gradually increased public relations and status of the object broke monopoly situation that the subject used to own in interactive communication. Web 2.0 makes everyone become a source of information on the Internet and the content is no longer led by a network employees. The interactive mode of communication affirms the status of the audience, and the object not only receive the message passively but also become the makers of the information. New media has changed the way of one-sided communication of public relations and the object of PR has seized the initiative in the whole process. Different from traditional media, in which the main body of public relation can freely screen and control the content of dissemination, the status of the main body has been weakened obviously with the promotion of new media technology.

The old and new media supplement each other meanwhile the communication effect has been improved.

Since the new media has been established the two-sided communication between the subject and the object,the subject of public relations can receive the feedback of the object more timely and evaluate and improve the communication.As a result, the communication effect under the new media environment becomes better and more effective.

For example, the company build an instant communication platform through the Weibo that people can publish instant views and then they can use it to solve their own problems according to the received feedback. Through this scheme they can set up a good corporate image and think about the after decision-making about public relations communication. Whether the audience or the company, both of them can benefit from the process. At the same time, the traditional media are also making constant change and update, even try to achieve their purpose of PR communication with 
the aid of the new media. An example is that traditional newspaper office has founded online electronic journals. New and old media compete with each other, from a mutual integration situation so that the effect of the transmission has been significantly improved.

\section{Issues and challenges faced by dissemination of public relation in New Media Age}

Due to diversity of dissemination channels, the mode of transmission taking characters, images and voices as carriers has become mainstream in new media age. For example, broadcasting is based on voices and TV is based on images. Different mode of dissemination put more requirements on richness and novelty, and push different medias of dissemination try to take a seat in dissemination of new media. As a result, more stringency is required on production or transmission contents in public dissemination.

\section{Information exploration brought by development of new media technique}

The concept of information exploration appeared in last century, and the widespread application of the technology of new media make this situation more prominent. Information dissemination with high speed and high efficiency makes us dizzying, and the birth of portable terminal makes it happen that great amounts of information can be disclosed anywhere at any time. The information disclosed from internet without administration is mixed with good and bad ones. Especially with huge amount of users by blogs and web forums and different levels of culture, it is hard for the public to identify normal and effective information. Consequently, communication subjects should consider how to make the information they release be accepted by the audiences.

\section{Out-of-control of information from active internet environment}

There are some advantages of new media dissemination including wide range of dissemination, low budget and accurate targeting. Currently, everyone can disclose information freely through internet as the main media, and the ways of dissemination are relatively flexible. This makes more and more people disclose various kind of information, at the same time more than more audiences are drove to publish their opinions, which makes internet more active. However, lots of sentimental views are created in the uncontrolled environment, which may have great influence with increased range of dissemination. Moreover, with rapid development of the new media, competition between individuals becomes more and more fierce. In order to achieve the effect of dissemination, many medias ore enterprises are finding every possible ways and take even unfair ways, which make the environment of internet more complicated. The kind of free dissemination of media increases of uncontrollability of dissemination of the new media.

\section{Blindness of choice of dissemination ways by main body of dissemination in PR activity}

Various ways of dissemination of new media bring great challenges when choices are face. When the main bodies of dissemination faces endless emergence of dissemination ways including digital magazine, digital newspaper, digital broadcasting, short messages, portable TV and internet, they need to choose the best ways of media or combination of media for dissemination, taking consideration dissemination effect of different new media ways, points of concern of audiences in combination of orientation, cost and contents of dissemination. However, blindness of choice is easily produced in this complicated circumstances in that real situation is neglected by following mainstream, or correct analysis can not be reached resulting wrong choices.

\section{High-freedom of information dissemination makes negative messages spread widely.}

Compared with the traditional media, the new media are less monitored, which enables the public to release information more freely, but makes the opinion on public affairs lack of management. The we-media, such as Facebook and blog, for its special channel of information dissemination and significant influence, can make the negative information that may be false or harmful to enterprise spread much quickly and leave an even more detrimental impact on the public. Furthermore, the we-media can release messages so immediate that accelerates the dissemination speed of negative information. This kind of situation can be related to "The butterfly effect" as we know. 


\section{Strategic of dissemination of public relation in the age of mew media}

\section{Establishment of real-time interactive platform}

Brand new communication mode and platform with full coverage should be provided, which makes communication and convergence of dissemination subjects between audiences. In this circumstances, the dissemination subjects and audiences own equal status, produce active dialog, publish opinions and views timely, so that the misunderstanding and problems between the two parties can be eliminated, and finally common perception can be reached in that based on realization of their own benefits, not only the public benefits are highlighted but also realize the consciousness of safeguarding the public interest. Even if there are conflicts between the two parties, the existence of the communication platform can maintain the mutual benefits, and facilitate the new co-operations between the two parties.

\section{"Gradient" control of dissemination information}

The meaning of gradient control of information can be interpreted as commanding the degree of information publication,and facilitating rationalization of information publication based on psychological need of the public in the status of crisis. The mechanism of gradient information publication can not be simply interpreted as limiting the quantity and speed of the information, it should be that the time and range of information publication should be decided by degree of impact caused to the public possibly caused by the public of information. Under the actual circumstance of crisis, the mental state of the public is that they urgently need to command and collect different kind of information in order to relieve the anxiety due to lack of the information. The best way in this circumstances is that rapid disclosure of abundant information in related to the the critical incident using all kinds of media, thus relieving the anxiety of the public. Since the media people have correct knowledge on the mental cognition of the public, the dissemination of public information should take the mechanism of the gradient publication in rational and scientific way.

\section{Make objects as the center and do Market segmentation of them.}

Under the circumstances of popularity of the new media, there is more than one way to realize PR dissemination. Also, the audience, as an essential part in information communication, the differences between individuals of that suggests a more complex situation. So, analyzing the audience exactly should be prioritized when disseminating information in order to boost degree of accuracy in dissemination of information. For audiences the effect would be better if the enterprise makes an appropriate choice in Communication mode. It's obvious that market Segmentation, dividing the public into demassification, plays an significant role in decision-making of dissemination, which contributes to a more effective result. It is known that traditional TV users are relatively younger than OTT users. As the <Internet (OTT) TV Audience Research Report $>$ shows, 18 - 34 year-old person predominately accounted for 53.8\% in OTT users, and 35-54 year old user accounts for 42.6 percent, however, only 3.6\% users are the person in over fifty years of age.As a consequence, the enterprise should devote more effort and investment on the OTT when aims to the younger generation in order to achieve the optimal transmission effect.

\section{Conclusions:}

Since the development of new media brings both opportunities and challenges to public relation dissemination, the dissemination subjects can only draw attention and interest of the related public, achieve effective communication with the public and reach the objective of public relation by continuously paying attention dissemination technique, changes of dissemination ways and structure, studying the environment faced by the consumer group, and designing proper dissemination contents. It is required that the PR individuals should consider based on long-term development, establish good images persistently, run the brand with great effort, strive for favorable market environment actively taking use of the more precise dissemination of public relation of the new media. 


\section{Reference:}

[1]R.Rice, C.K Atkin:Public Communica-tion Campaigns, Sage Publications,London (2000), in press.

[2]Rawlins $\mathrm{W} \quad \mathrm{K}$ : Theorizing public and private domainsand practices of communication:introductoryconcerns [J]. Communication Theory, 1998, 8(4): 369-380.

[3]David Croteau, William hoynes. Media operations in commercial media and the public interest, Tsinghua University Press, Beijing (2007), in press.

[4]Fulk J, Flanagin A, Kalman M, Monge P, Ryan T: Connective and communal public goods in interactive communication systems. Communication Theory,1996,6(1): 60-87.

[5] Nielsen-CCData: Internet (OTT) TV Audience Research Report 